\title{
A Review of Scenario and Status of Natural Resource Management Practices in Nepal
}

\author{
Manoj Sharma* \\ Department of Agricultural Economics and Agribusiness Management, Agriculture and Forestry University, Chitwan, Nepal \\ *Corresponding Author: Manoj Sharma, Department of Agricultural Economics and Agribusiness Management, Agriculture and Forestry \\ University, Chitwan, Nepal.
}

Received: June 13, 2019; Published: September 16, 2019

DOI: 10.31080/ASAG.2019.03.0651

\begin{abstract}
The paper addresses natural resource management practices in Nepal which are adopted and still remained to adapt especially for the management of land, watershed, forest and other plants, and animal lives. This is followed by inclusion of the traditional and present - day practice systems of natural resource management which helps in the identification of factors and processes contributing to resource degradation. Lessons from past systems and successful experiences of new initiatives and practices of natural resources management are discussed to suggest possible approaches to rebuilding communities' natural assets. The final section of the paper looks at concerns that government should focus to have sustainable natural resource management. The crucial role of natural asset building in sustainable development by conserving, regenerating, upgrading, and equitably harnessing natural resources, particularly forests, pastures, and their links with crop lands stems from the contributions of these resources towards enhancing the qualitative livelihood. These include direct availability of seasonally and spatially varying supplies of bio - fuel, fodder, fiber, food items, timber, and high-value products such as medicinal herbs, honey, mushrooms, and vegetable dyes. The indirect services provided by forests and other natural ecosystems include stability of the micro-environment and the flow of moisture and nutrients to sustain productive farming systems.
\end{abstract}

Keywords: Bio-Diversity; Conservation; Management; Natural Resource; Protection

\section{Introduction}

Natural resource are very important to human life as they provide different utilities like clean water, fresh air, biological resources, food and fibers, and other ecosystems services. Nepal is rich in natural resources and is gift for Nepal. The major natural resources of Nepal are forestry, water resources, land, biodiversity and other minerals. However, the increasing demands for these natural resources due to the growth of the human population on one hand, and haphazard uses, forest firing, anthropogenic interventions and natural calamities on other hand calls for sustainable management of natural resources urgently. Such management requires an interdisciplinary approach including in - depth knowledge about specific resources as well as a holistic perspective, including ecological, economic and social aspects. It also requires a strong ability to communicate in order to establish dialogues between the different disciplines involved as well as between the stakeholders, and a good understanding of the connections between these different actors. The underlying question in natural resource management in Nepal is how to improve the management of land, forest, and water resources in order to maintain both the productive capacity and ecological functions of these resources. Nepal is hardly the only country where improving natural resource management is a development issue. However, during the past two decades significant loss and damage to forests, soils, and riverine systems in many areas of Nepal have led to widespread environmental damage and declining agricultural productivity, underscoring the urgency to develop practical measures to reestablish a sustainable agricultural production system. Therefore, the cost - effectiveness of natural resource management approaches in Nepal must be considered carefully by the Government of Nepal and the donor community.

\section{Concept and Literature Review}

In this section, definitions of key concepts used in the study are presented. The section begins with concepts such as conservation, natural resources, and natural resource management.

Natural resource management is central to global efforts to reduce environmental degradation and advance sustainable development [1]. The world in which man lives contains a number of resources. These resources make it possible for man to exist on the planet earth and reproduce after its own kind, and produce goods and services to meet its needs. Man did not create these 
resources; we met them here, existing "in nature". Consequently, these resources have come to be known as "natural resources", simply because they occur naturally. These resources include the geophysical resources of water, soil and its productive qualities, intermediate and long - term carbon stocks, biodiversity of the managed landscapes, and the stability and resilience of the ecosystem of which agriculture is a part [2].

The term conservation came into use in the late 19th century and usually involves the active management of natural resources to ensure long - term viability of a resource, but in some cases, conservation means leaving the land and wildlife alone [3]. Conservation also means intelligent use of resources so that they can be utilized to the fullest without being depleted [4]. Conservation has been put forth as the means to rehabilitate native biota, their habitats and life support systems to ensure their sustainability and biodiversity [5].

The word resource has been interpreted narrowly as denoting a physical entity such as land, forests, plants, fuel - wood, water and certain wild animals [5]. In contrast, natural resources are naturally - occurring resources that are considered valuable to people and in their relatively unmodified form [6]. Natural resources are often classified into renewable and non - renewable resources. Renewable resources include living resources such as fish, cocoa, rubber, coffee, and forests which can restock or renew themselves if they are not over - exploited. As the name implies, nonrenewable resources cannot restock themselves and are finite. Non - renewable natural resources can be listed as fossil fuels, oil, coal, copper, diamonds, natural gas, iron ore, minerals, gold, silver, platinum, rocks, and many more. Once non - renewable resources are removed, they cannot be replaced. The rate of sustainable use of a renewable resource is determined by the replacement rate and the amount of standing stock of that particular resource. Once renewable resources are consumed at a rate that exceeds their natural rate of replacement, the standing stock will diminish and eventually run out. At this point, a natural resource could be said to be overexploited which calls for proper resource management.

Management as defined by Frew [7], consists of planning, organizing, motivating and directing. It means directing or steering of things by any means possible [8]. Management can also mean guiding or controlling and can refer to setting goals and taking actions to fulfill those goals [6]. Natural resource management therefore entails the management of natural resources so as to ensure sustainability [9]. In other words, natural resource management involves the ability to formulate and implement effective goals with the objective of achieving a sound and ecological environment. A number of natural resource management approaches exist but the most practical for nature conservation at the community level is community conservation.

INRM is "an approach that integrates research on different types of natural resources, into stakeholder - driven processes of adaptive management and innovation, to improve livelihoods, agro ecosystem resilience, agricultural productivity and environmental services, at community, eco-regional and global scales of intervention and impact" $[10,11]$. It involves the integrated analysis and management of the components of production, in such a way that one is able to achieve the products required by man for survival, while maintaining environmental balance and sustainability. INRM operates on the principle that natural resources are neither indestructible nor infinite; they can be destroyed or depleted through agriculture and other land use practices. They require to be managed in a holistic and integrated manner, accounting for the complexity of the ecosystem and the inter - relations amongst its various components.

Community - based natural resource management is central to many efforts to reduce environmental degradation. The underlying philosophy of community - based natural resource management approaches states that under the right conditions and incentives, people will manage wildlife and other natural resources sustainably [12].

Of all the conservation activities operating in protected areas worldwide, nature-based tourism, and in particular, ecotourism reigns supreme for two major reasons. First, tourism or ecotourism is seen as a conservation tool having the power to preserve the world's natural resources. Secondly, it is recognized as a catalyst for socio - economic change offering significant opportunities for employment creation and local economic development [13].

The convention on biological diversity encourages national governments to adopt economically and socially - sound measures, for example tourism development in PAs, to provide incentives to local people in return for their support towards conservation [14].

With increasing concern about biodiversity and nature conservation locally and internationally, several countries signed agreements, created protected areas, passed conservation laws and established institutions targeted at specific plant or animal species designated as having international or national importance to address the problem of natural resource exploitation. In spite of this, studies have shown that some protected areas continue to experience heavy exploitation of their natural resources; both wild animals and wild plants [15]. This may be due to the fact that most conservation laws and designations of protected areas, such as national parks and wildlife sanctuaries in developing countries, followed the 'preservation - oriented' approach, which advocated centralized - regulatory control and the exclusion of local people [16].

The concept of natural resource management is management such as land, soil, water, plants and animals with a particular focus on how management affects the quality of life for present and future generations (stewardship). It deals with managing the way in which people and natural landscapes interact through the use of practices related to land use planning, water management, biodiversity conservation and the future sustaining efforts. 


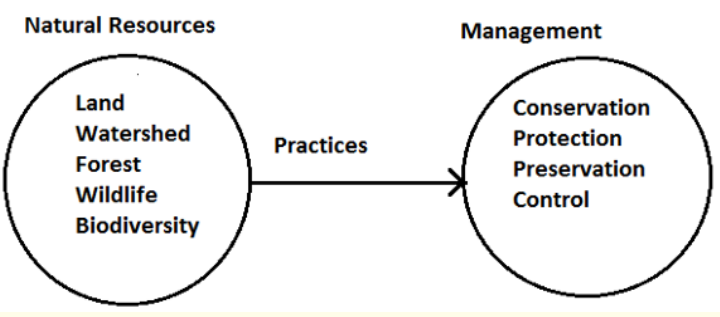

Figure 1: Conceptual framework for Natural resources management.

\section{Key Findings and Discussion}

There are different methods of conservation practices of natural resources. However, the sole concept of natural resource management revolves around the management of land, water and forest.

Land resource management practices

Agro forestry

Agro forestry is the practices of combining the agriculture with forestry to conserve the land. The system is increasingly being adapted in the middle hills of eastern Nepal. The aim of developing agro forestry within Nepal is to meet the present and future requirement of fuel wood, small timber, fodder and natural resources protection. The substantial diversity of trees in traditional agro forestry system complements their important role for the sustainability of the agricultural production. Traditional agroforestry practices benefit biodiversity through in-situ conservation of tree species on farms, reduction of pressure on remaining forests, and the provision of suitable habitat for plant and animal species on farmland [17].

\section{Conservation tillage}

The practices of minimum tillage, zero tillage reduces the exposure of dry soil to outer environment. Similarly, they are helpful to moisture conservation. So the degradation of fertility due to erosion reduces. For example, zero tillage for wheat cultivation in Terai is becoming popular. Relay cropping of lentil to rice field is also good practice adopted in Nepal.

\section{Stubble mulching}

It can be widely used in sub - humid and semiarid regions. Stubble is any crop residue left standing after harvest. Wheat stubble/ corn stalks are uniformly spread on soil surface. Land is tilled that permit most of plant residues to remain near surface which help to minimize surface disturbance. So that, soil surface is protected from structural damage, soil erosion and also improves moisture retention. According to Atreya, Bajracharya, Rajbhandari, and Sharma [18], reduced till was found effective in terms of minimizing soil and nutrient losses. Soil nutrient losses from conventional till were found very high, which may be one of the major causes of fertility depletion in the hills of Himalayan Kingdom.

\section{Contour cultivation and bench terracing}

It is the practice of ploughing, harrowing, and furrowing along the contour of the land which helps to minimize scouring of soil by surface runoff. Ultimately, it reduces quantity and velocity of runoff, and hence reduces surface runoff and soil loss. Terracing and contour cultivation could minimize soil erosion and help to restore the physical and chemical property of the soil. These restoration methods, however, may only be effective under specific edaphic conditions and have limited applicability on steep slope land [19].

In hilly area mainly for the cultivation of rice, level terraces are made for retaining the water, while sloping terraces (10 to 15 percent) are built for rainfed cultivation. The slope and width of the terraces are determined by the topography: the steeper the topography, the higher the slope gradient of the terrace and the narrower the width. The width of the sloping terraces varies from 2 to $3 \mathrm{~m}$, making the parcel size quite small. Rice is cultivated on level terraces, if irrigation water is available and the temperature is suitable. Elevation, which controls climate, determines the variations in land cover and land use types.

\section{Composting and crop residue management practices}

Compost is generally prepared in the field and is an appropriate technology for those farmers who own no or less livestock and/ or whose farm land is very far to transport FYM. Compost can be prepared in the field using locally available crop residues, vegetation from terrace riser and other farm area, forest litter etc. It avails organic manure to the soil where alternative is limited and also reduces the transportation cost and time. By minimizing cost and application of chemical fertilizers, it improves SOM and soil nutrient level. Besides, biomass burning and uprooting legume is avoided. Crop residues can be incorporated into soil and also used as livestock bedding. These practices can help to reverse the situation of continued biomass removal from agricultural soil, and supplement the SOM and major plant nutrient level [20].

Adoption of mechanical engineering and Bioengineering techniques

Bioengineering uses plants/trees whereas civil engineering use construction of physical structures (dams, walls, terrace etc.) to prevent the soil erosion. Few bioengineering techniques for land and soil conservation practices are brush layer, conservation plantation, grass planting, hedgerow planting on sloping land, palisade, Watling, riprap, grass waterway, fascine, jute netting etc. Similarly, mechanical engineering techniques include check dams, retaining walls, embankment, water ways, spillways, terracing etc. In Nepal, civil engineering techniques are found in road asides of many parts of country. But, bioengineering is not so popular. However, use of grasses like vetiver, bhojetro i.e. bioengineering has succeed in krishnavir of Kathmandu district [21]. 
Integrated watershed management approach

IWM is the integration of technologies for optimum development of land, water and plant resources within a watershed to meet the basic needs of people and animals in a sustainable manner. It includes combination of various activities like agricultural management, agri - silvi pastoral management, soil and water conservation, water harvesting/management, supplemental irrigation, horticultural management, community forestry, forest regeneration and management, reforestation, income generation activities; so on [22].

A watershed approach is a flexible framework for managing natural resource quality and quantity within the specified drainage areas. This approach includes stakeholder involvement and management actions supported by sound science and appropriate technology. The watershed planning process works within this approach by using a series of cooperative, iterative steps to characterize existing conditions, identify and prioritize problems, define management objectives, develop protection or remediation strategies, and implement and adapt selected actions as necessary.

Forest and pasture land management practices Afforestation and rotational grazing

Vegetations (reforestation/afforestation) play major role in erosion control on gullies areas and landslides - forestation programs should be prioritized. For example: Bamboo plantation increases biodiversity as they are place for birds, small animals and also very helpful in land conservation [23].

Large sized plant leaves give rise to large drop of water. So, complete removal of litter and grasses should be avoided. Overgrazing of forest not only destroys natural vegetation, it compacts soil, destroys aggregates and reduces infiltration. Grazing should be permitted in a limit not causing environmental hazard. Proper drainage should be provided while road runs across the forest land. Adoption of the bioengineering system has been very effective erosion control measure. Adoption of agro forestry would be a good strategy to reduce soil erosion in forest land.

\section{Community forestry}

Community forestry is based on the operational co - operation of Forest Department officers and forest user groups. Moreover, the devolution of the power and authority to manage forest areas between these actors is linked to the idea of sharing the responsibility of forest protection. Recently, the percentage of forest and shrub land in Nepal has found to be increased to about $44 \%$. The main reason behind this is contribution of community forestry in Nepal. Dialogues between communities and the state for establishing forestry projects have progressed regarding the issue of handing over a defined area of government forest to community control, so that all sections of communities participate in the formation of a legally - recognized forestry user group which follows the government's community forestry regulations [24].

\section{Production of fodder and forage crops}

Planting of both fodder and forage crops in crop rotation, on terrace riser, or on ridge and wasteland around farm, which often account for $25 \%$ of farm area. Thus it well utilizes marginal and unused land reducing the risk of soil erosion and nutrient loss. On farm production of fodder and forage crops is an appropriate strategy to provide livestock with improved (quality) feed for enhanced livestock production. It re - cycles nutrients, and builds resilience of local agro - ecosystem. Added benefits of small on - farm fodder and forage plantation include the fact that it encourages stall feeding and reduces workload of women, significantly decreasing time and energy associated with collecting fodder for their livestock from off - farm location. It thereby reduces pressure on forest for supply of fodder and forage. Incorporation of multi - purpose fodder species also provides several economic benefits, like wood, herbal medicine, timber, fruits etc. [25,26].

It improves soil structure and fertility, thus rain soaks into soil more readily resulting in water table replenishment (especially in desert and dry areas), thereby making water more accessible to plants, livestock and people. Other advantages include increasing resilience of farming system to extreme weather events, diversifying sources of food and income, protecting land and water resource, and sequestering carbon into soil, root and biomass.

Examples of natural resources management practices in different parts of Nepal

The traditional farming practices employed on steep sloping land in Kehinde village in Nepal's mid hills led to soil and water erosion and low crop and fodder yields. The People and Resource Dynamics in Mountain Watersheds of the Hindu Kush - Himalayas Project (PARDYP) started work in 2001, with a small group of farmers from this village (who were also members of the local forest user group) and the Department of Soil Conservation and Watershed Management to identify and test an integrated approach for addressing these constraints. The approach taken was an improved hill terrace for rainfed conditions consisting of structural and vegetative measures.

The soil and water management practices are promoted by the Swiss - funded Sustainable Soil Management Program (SSMP), and implemented in several districts in mid-hills of Nepal from 1999 to 2014 by HELVETAS Swiss Inter cooperation. These practices are largely based on efficient and sustainable use of locally available resources, and include improved farmyard manure (FYM) and compost management techniques, systematic collection of cattle urine and its use as liquid fertilizer and a base for botanical pesticide, integrating legumes into cropping system, and fodder and forage plantation. These practices, which are combined with promotion of seasonal and off - season vegetable and cash crop production and introduction of improved cereal varieties, and water management strategies result in improved farm productivity, income and food security as well as greater resilience to climatic variability and reducing women's workload. 
Institutional framework of government of Nepal on natural resource management

Soil Conservation and Watershed Management (SCWM) program was for the first time recognized as an important program by the Government in 1974 when a new department, Department of Soil and Water Conservation, was established under the umbrella of the Ministry of Forests. Later the name of the department was changed to Department of Soil Conservation and Watershed Management (DSCWM). After that Soil Conservation Offices were established in districts basis. At present DSCWM is providing SCWM service to 75 districts of Nepal through 61 DSCOs.

An "Organization and Management Study", which was recently conducted recommended for switching to the basin approach from the existing political boundary approach for the implementation of the SCWM program. Now, the DSCWM is planning to convert the current management system to the basin approach. DSCWM prepared a log - frame of Soil Conservation and Watershed Management Program since the Fiscal Year 2063/64 and the Ministry of Forest and Soil Conservation has approved the log - frame.

\section{Conclusion and Recommendation}

This discussion focused on practices and factors helping natural resource management in Nepal. The practice for natural resource management include agroforestry, conservation tillage, stubble mulching, bench terracing, contour farming, bioengineering techniques etc., for land resource management while community forestry, rotational grazing, vegetation covers are practices for forest and pasture resources conservation. The conservation of natural resources is linked with sustainable development of country. So, there are still so many spaces for policy interventions and implications to conserve the natural assets of country. Natural resource management (NRM) is becoming a relatively contextual issue and expanding thrust in policy interventions in Nepal. In past days, there are some polices related to natural resource management like Soil and Watershed Conservation Act (1982), Soil and Watershed Conservation Regulation (1985), Forest Policy, 2014, Environmental Protection Act (1996) etc. However, many of studies have concluded that if natural resources are to be protected against the risk of destruction, it is essential that governments devise a range of policy instruments that can influence behavior for the adoption of technology innovations and institutions that promote sustainable management of natural resources.

1. Government should focus on strengthening of social - capital i.e. the self-organizational capacities within communities, and create conditions in which local people are able to formulate, review, monitor and implement appropriate byelaws, and engage in mutually beneficial collective action for resource conservation. In the absence of legal framework for people's participation in the past, influential persons tried to get all the benefits of a project's activities in the name of community participation.

2. Government must be cognizant of the fact that human resource capacity is low and should endeavor to enhance it through formal classroom education, on-the-job training as well as through other academic programs designed in the line of nature conservation, ecotourism design and development. Training should focus on park management as well as local community members - to know and appreciate the importance of nature conservation. Government should also provide adequate financial support to enable effective management and achievement of designed/proposed strategic plans for its protected areas.

3. Equally important is the provision of necessary infrastructure and other vital amenities such as all weather roads, markets, schools, alternative energy sources such as electricity and liquid petroleum gas. The availability of these facilities and amenities could attract potential investors to the region. The development of business opportunities in the region could in turn create jobs for people in the region. So that the dependency over natural resources could be reduce.

4. Landslide inventory and documentation, hazards mapping, gully treatment, landslide treatment, torrent control, and stream bank protection activities using various engineering and vegetative measures may be required for the disaster risk reduction in practice. Check dams, retaining walls, diversion channels, grass sowing, and tree planting are the main types of works under these activities. Most of these activities would be in uncultivated streambeds, or on steep slopes, or on the area of lesser economic return, or on public lands; therefore, treatment usually causes minimum disruption to local land use. So, while implementing these activities, objections from the local people regarding ownership is less likely. However, these measures are very expensive and people's participation in cash will be more difficult. For this, government should focus its policy intervention and formation.

\section{Bibliography}

1. Lenton R. "Managing Natural Resources in the Light of Climate Variability”. Natural Resources Forum 26.3 (2002): 185-194.

2. CGIAR. "Research towards Integrated Natural Resources Management". CGIAR Interim Science Council (2003).

3. Thoms C A and D R Betters. "The Potential for Ecosystem Management in Mexico's Forest Ejidos”. Forest Ecology and Management 103.1-2 (1998): 149-157.

4. Chapman SG and J Hartman. "Conservation Law Enforcement in Michigan". Journal of Criminal Law, Criminilogy and Police Science (1962): 383-390.

5. Shuter BJ., et al. "Reply: Toward a Definition of Conservation Principles for Fisheries Management". Canadian Journal Fisheries Aquatic Science (1997): 2724-2725. 
6. Eagles PFJ. "Environmental Management". Parks and Protected Areas in Canada: Planning and Management (2002): 416.

7. Frew DR. "Toward a Redefinition of Management". The Academy of Management Journal (1971): 396-398.

8. Knudson R. "Cultural Resource Management in Context. Archives and Museum Informatics". Archives and Museum Informatics 13.3-4 (2001): 359-381.

9. De Beer F and M Marais. "Rural Communities, the Natural Environment and Development- Some Challenges, Some Successes". Community Development Journal (2005).

10. Task Force on INRM. Integrated Management for Sustainable Agriculture, Forestry and Fisheries: A brief report on the INRM. Cali, Colombia: CIAT (2001).

11. INRM. Task Force on. Integrated Management for Sustainable Agriculture, Forestry and Fisheries: A brief report on the INRM workshop held at CIAT. Cali, Colombia INRM (2001).

12. Johnson C. "Community Formation and Fisheries Conservation in Southern Thailand". Development and Change 32.5 (2001): 951-974.

13. Garrod B. "Local Participation in the Planning and Management of Ecotourism: A Revised Model Approach". Journal of Ecotourism (2003): 33-53.

14. Walpole MJ and H J Goodwin. "Local Attitudes towards Conservation and Tourism around Komodo National Park, Indonesia”. Environmental Conservation 28.2 (2001): 160-166.

15. Bawa K S and R Seidler. "Natural Forest Mangement and Conservation of Biodiversity in Tropical Forest". Conservation Biology (1998): 46-55.

16. Mehta JI and SR Kellert. "Local Attitudes Toward Communitybased Conservation Policy and ProgrammesLocal Attitudes Toward Community-based Conservation Policy and Programmes in Nepal: A Case Study in the Makalu-Barun Conservation Area". Environmental Conservation (1998): 320-333.

17. Neupane RP., et al. "Adoption of agroforestry in the hills of Nepal: a logistic regression analysis". Agricultural Systems 72.3 (2002): 177-196.

18. Atreya Kishor, et al. "Applications of reduced tillage in hills of central Nepal". Soil and Tillage Research 82.1-2 (2006): 16-29.

19. Kerkhoff EE. "Debating shifting cultivation in the Eastern Himalayas: Farmers' innovations as lessons for policy". (2003).

20. Mandal KG., et al. "Rice residue-management options and effects on soil properties and crop productivity". Journal of Food Agriculture and Environment (2004): 224-231.
21. Florineth FHP Rauch and H Staffler. "Stabilization of landslides with bio engineering measures in South Tyrol/Italy and Thankot/Nepal". International Journal in Pacific Rim-Matsumoto (2002): 827-837.

22. Gautam APGP Shivakoti and E L Webb. "Forest cover change, physiography, local economy, and institutions in a mountain watershed in watershed in Nepal". Environmental Mangement 33.1 (2004): 48-61.

23. Jackson JK. "Manual of Afforestation in Nepal". Kathmandu Nepal: Forest Survey and Research Office, Department of Forest (1987).

24. Ingles AW. "Community forestry in Nepal". Conserving Biodiversity outside Protected Areas (1995): 183-204.

25. Bishwakarma BK., et al. "A Handbook of Technologies and Extension Approaches from the Sustainable Soil Management Programme". Kathmandu, Nepal: Sustainable Soil Management Programme (SSMP) (2014).

26. Mahanty S and D Russel. "High Stakes: Lessons from Stakeholder Group in the Biodiversity Conservation Network". Society and Natural Resources 2 (2002): 179-188.

\author{
Volume 3 Issue 10 October 2019 \\ (C) All rights are reserved by Manoj Sharma.
}

